\title{
Extraction and adsorption of U(VI) from aqueous solution using affinity ligand-based technologies: an overview
}

\author{
Jianlong Wang $(\mathbb{D} \cdot$ Shuting Zhuang
}

Published online: 26 July 2019

(C) The Author(s) 2019

\begin{abstract}
In terms of energy resource recovery and environmental protection, the separation of $\mathrm{U}(\mathrm{VI})$ from aqueous solutions is vital. Adsorption and solvent extraction are the most common separation technologies, which are also widely used for uranium recovery or removal from aqueous solution. The linear structure of uranyl ion and its multiple coordination feasibilities offer great opportunities for its extractive and adsorptive separation. This review briefly summarized and analyzed the recent advances in the separation of uranyl ions from aqueous solutions, mainly focusing on the selective extraction and adsorption using affinity ligands-based technology, which is promising method due to the high selectivity, capable of recovering uranium at low concentration and complicate aqueous environment. The affinity ligands for uranyl ions, including organophosphorus, calixarenes, amidoxime, imidazole and other derivatives were introduced. These donor ligands for design of extraction solvents or adsorbents for the separation
\end{abstract}

J. Wang $(\bowtie) \cdot$ S. Zhuang

Collaborative Innovation Center for Advanced Nuclear

Energy Technology, INET, Energy Science Building,

Tsinghua University, Beijing 100084,

People's Republic of China

e-mail: wangjl@tsinghua.edu.cn

J. Wang

Beijing Key Laboratory of Radioactive Waste Treatment,

INET, Tsinghua University, Beijing 100084,

People's Republic of China of uranyl ions were summarized. The further research on the coordination chemistry towards uranyl ions and removal mechanisms would provide vital information for the development of more effective ligands with higher affinity, stability and compatibility in various systems, which is still challenging.

Keywords Uranium · Adsorption · Extraction · Amidoxime $\cdot$ Calixarenes

\section{Introduction}

Uranium (U) is an indispensable resource for nuclear fuel and a hazardous radionuclide of chemical toxicity or radioactivity at the same time. U(VI), in the form of uranyl ion $\left(\mathrm{UO}_{2}{ }^{2+}\right)$ and its various complexes, are soluble and widely existent in radioactive wastewater and seawater. A large quantity of U-containing wastewater is generated from the whole process of nuclear industry, from mining, processing, to reprocessing. For the recovery of uranium resource and the security of ecosystem, the selective isolation of U(VI) from aqueous solutions is of great importance.

The selective separation of uranyl ions can be achieved by extraction and adsorption methods based on the ligands of high affinity towards uranyl ions (Kiegiel et al. 2013). The comparison of the extraction and adsorption technologies, including the advantage, 
disadvantage, removal rate and mechanism are briefly summarized in Table 1.

Uranyl ion is distinctive because of its linear structure $\left(\mathrm{O}=\mathrm{U}=\mathrm{O}^{2+}\right)$ (Fig. 1) owing to the $5 \mathrm{f}-6 \mathrm{~d}$ orbital hybridization of U (Bart and Meyer 2008; Denning 2007). It can coordinate with atoms on the equatorial plane perpendicular to its linear structure, forming a configuration of quadrilateral, pentagonal or hexagonal bipyramids (Fig. 1). At specific coordination environment, distortion of these configurations may also occur. So far, several types of donor ligands (e.g. amidoxime, amide, imidazole, organophosphorus, and calixarene derivatives) with a high affinity towards uranyl ions have been studied. These ligands have been employed in the process of solvent extraction or in the construction of adsorbents, and they presented a good separation performance towards uranyl ions (Abney et al. 2017; Manchanda 2004; Zhuang et al. 2018; Zhuang and Wang 2019).

There are several comprehensive reviews and reports on the uranium recovery from seawater or uranium removal from contaminated water (Chareyron et al. 2014; IAEA 1993; Katsoyiannis and Zouboulis 2013; Kim et al. 2013; Leoncini et al. 2017; Lindner and Schneider 2015; Veliscek-Carolan 2016; Husnain et al. 2018; Li et al. 2018; Madic et al. 2007). Aly and Hamza (2013) summarized different technology for U removal. Leoncini et al. (2017) and Abney et al. (2017) elaborated the knowledge regarding ligands for f-element extraction and adsorbent for the recovery of uranium from seawater, respectively. Kiegiel et al. (2013) summarized calixarenes' application in solvent extraction and solid-phase extraction for the separation of $\mathrm{UO}_{2}{ }^{2+}$. Radionuclide preconcentration and separation by solid-phase extraction technology was also reviewed by Mokhodoeva et al. (2011). These reviews elaborate the development of

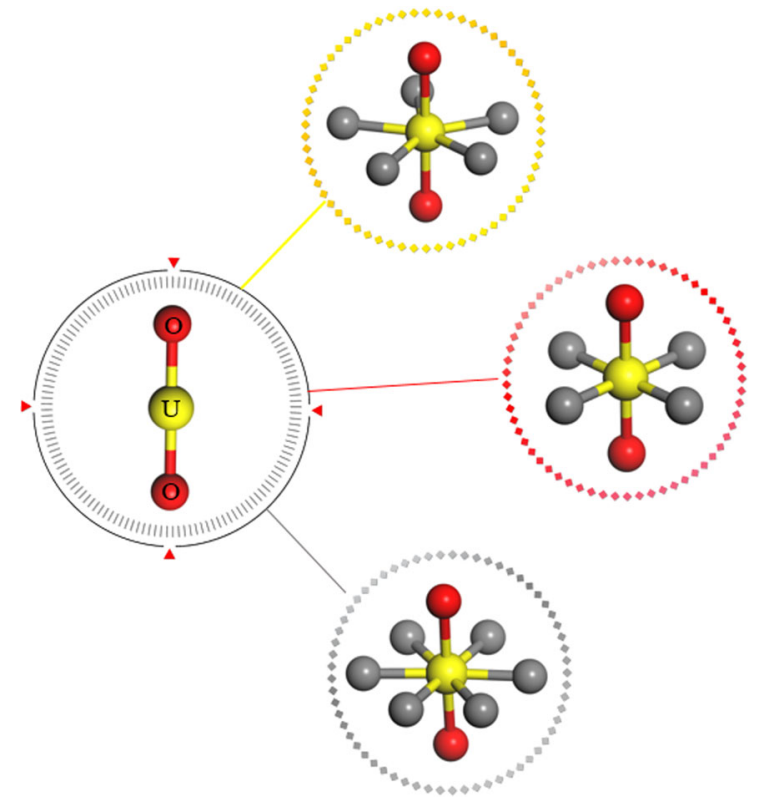

Fig. 1 The linear structure of uranyl ion, and its quadrilateral, pentagonal and hexagonal bipyramids coordination configurations (the grey balls stand for coordinating atoms)

various technologies or mainly focus on specific technology. However, the specific review on the aspect of uranium separation technologies (extraction and adsorption) based on the coordinating agents is not yet sufficient. It would provide valuable insights into the design of new selective adsorbents towards uranium and the understanding of their adsorption mechanisms.

The goal of this review is to summarize affinity ligands-based methods, mainly solvent extraction and adsorption, for the selective separation of uranyl ions from aqueous solutions. Affinity ligands towards uranyl ions and their utilization in both fields are

Table 1 The comparison of adsorption and extraction technologies

\begin{tabular}{llll}
\hline Technologies & Advantages & Disadvantages & Mechanism \\
\hline Extraction & (1) High separation factor & (1) Third-phase formation & Chelation; ion-association; etc. \\
& (2) High selectivity & (2) Generation of secondary waste & \\
(3) Energy saving & (3) Solvent losses & Coordination; ion exchange; etc. \\
Adsorption & (1) Low cost & (1) Low selectivity & \\
& (2) High capacity & (2) Regeneration & \\
& (3) Easy operation & & \\
\hline
\end{tabular}


introduced. The comparison between both methods based on these ligands were also discussed.

\section{Solvent extraction}

Solvent extraction is based on the thermodynamic stability of different complexes in the different media. This method is known for high separation factor, low cost and energy saving. Uranium is the first element recovered by this method in large quantities (Aly and Hamza 2013). However, the solvent loss and reagent cost on the large scale applications reduce the economics of harvesting uranium from seawater, where adsorption method is more popular.

For practical use, extractant is required of a high affinity for uranyl ions, together with a good radiolytic and hydrolytic stability. According to the ' $\mathrm{CHON}$ ' principle, extractants composed of only these atoms $(\mathrm{C}, \mathrm{H}, \mathrm{O}$, and $\mathrm{N})$ are preferable because no solid, radioactive residues would be produced after incineration (Kolarik 2008).

Over the years, many ligand systems have been developed for uranyl ions' selective extraction, and several commercial processes have been proposed and widely utilized in the separation of actinide (typically U) from spent nuclear fuel (Veliscek-Carolan 2016). Many factors, including the concentration of uranyl ions, coexisting ions, and $\mathrm{pH}$ of the solutions, have influence on the extraction performance. Despite development of ligands, the focus of research has also been given to the development of alternative solvents, such as hydrophobic ionic liquids (Stockmann and Ding 2011; Cocalia et al. 2005).

\subsection{Organophosphorus compounds}

Since 1990, organophosphorus compounds have been widely utilized in uranium extraction process owing to their good coordinating ability towards uranyl ions. Figure $2 \mathrm{a}$ presented some examples of the widely reported organophosphorus compounds utilized in uranium extraction (Aly and Hamza 2013), and many of them are commercially available.

Currently, the most widely used commercial process for uranium separation from spent nuclear fuel dissolved in nitric acid is based on solvent extraction, namely Plutonium Uranium Reduction Extraction (PUREX) process (Lanham and Runion 1949). This process employs organophosphorus compound, namely tributyl phosphate (TBP), in long chain aliphatic hydrocarbon as solvent. The TBP-based PUREX includes three stages: the extraction of $\mathrm{U}(\mathrm{VI})$ and $\mathrm{Pu}(\mathrm{IV})$ by $30 \% \mathrm{TBP}$ in kerosene from spent nuclear fuel dissolved in 3-6 $\mathrm{M}$ nitric acids; the separation of $\mathrm{Pu}$ from organic phases by reducing agents; and the stripping of $\mathrm{U}(\mathrm{VI})$ by dilute nitric acids. The extracted U(VI) are converted into oxides for reuse. This commercial process is technically and economically feasible for uranium recovery from spent nuclear fuel.

Since 1954 until today, tributyl phosphate (Fig. 2a) is the most technologically important extractant in processing and reprocessing of nuclear fuels (Paiva and Malik 2004). It demonstrates a good hydrolytic stability at extremely acidic conditions, and a good selectivity towards U(VI) with a high decontamination factor $\left(10^{6}-10^{8}\right)$ (Sood and Patil 1996). The possible complexation stoichiometry between TBP and uranyl ions in $\mathrm{HNO}_{3}$ solutions (Stockmann and Ding 2011) using electrochemistry method is given in Fig. $2 b$. Complexation constants of $3.2 \times 10^{11}(\mathrm{n}=3)$ and $3.9 \times 10^{13}(\mathrm{n}=4)$ are identified by interfacial complexation reactions (Stockmann and Ding 2011). In high radiation environments, and will be gradually degraded during the extraction process (Mincher et al. 2009). This will affect the separation performance of TBP-based extraction process over time, because the dominant degradation product, dibutylphosphate, presents different extraction behaviors to TBP (e.g. a high affinity towards $\mathrm{Zr}$ ) and will stimulate the formation of third phase. Washing with sodium carbonate is an effective way to remove its degradation products, but it is time-consuming. But for TPB-based adsorbents, TBP degradation would not be a problem for $U$ recovery from seawater or mining waste, etc.

Other important organophosphorus ligands widely used in processing and reprocessing of nuclear fuels is the octyl(phenyl)-N,N-diisobutylcarbamoyl methylphosphine oxide (CMPO), whose structure is given in Fig. 1a. In TRans-URanium EXtraction (TRUEX) process (a modified form of PUREX), a combination of 1.2 M TBP and 0.2 M CMPO was utilized in paraffinic hydrocarbon diluent. The phosphine oxides of CMPO present a good coordination ability towards uranyl ions at acidic environment (Stockmann and Ding 2011) (Fig. 2a) and overcome the formation of third phase. The improved 


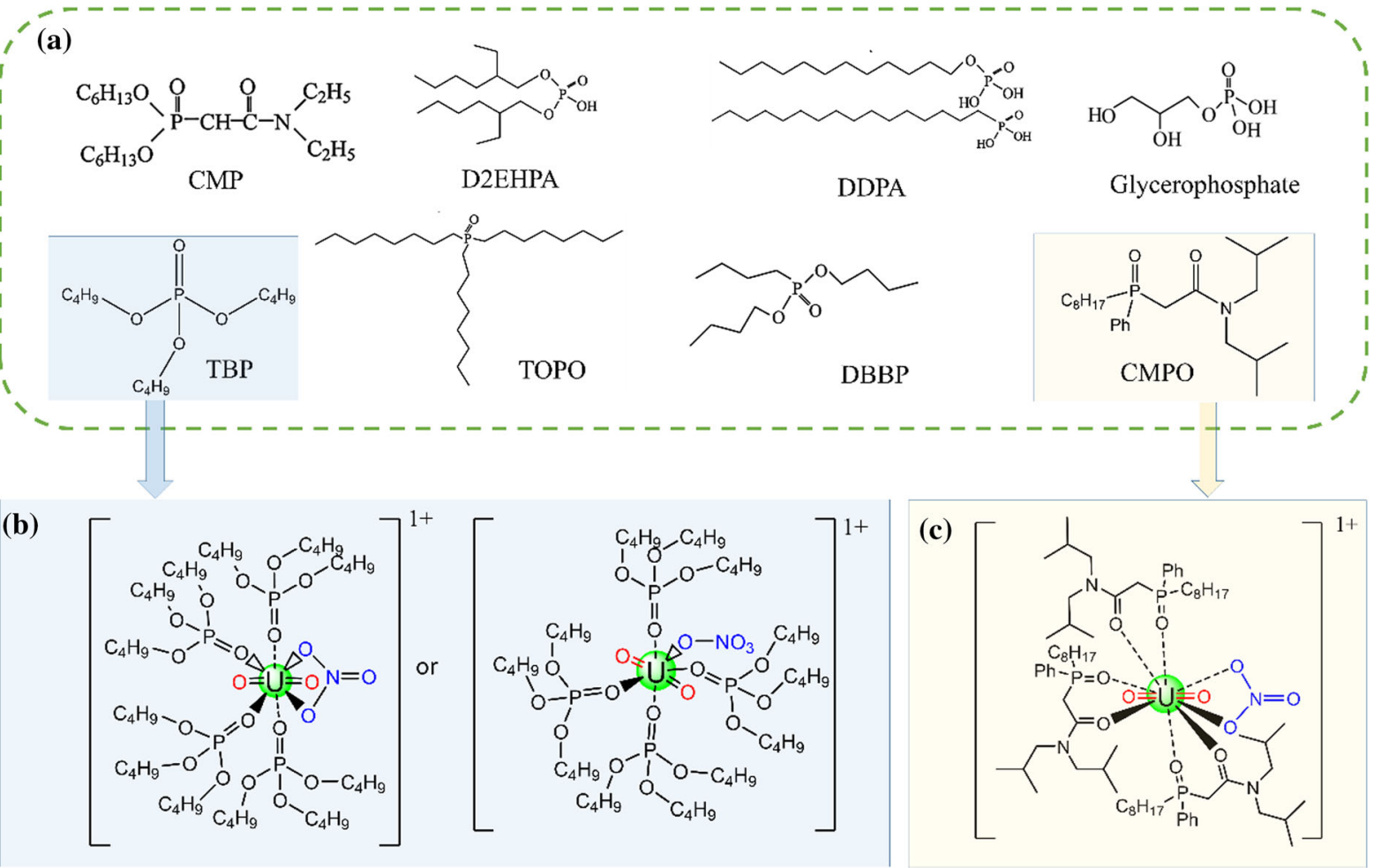

Fig. 2 The examples of reported organophosphorus compounds utilized for uranium extraction (a); the possible coordination configurations between TBP and uranyl ions (b), as well as CMPO and uranyl ions (c)

performance of CMPO derivative ligands could be obtained by construction them onto tripodal scaffolds (Sartain et al. 2015) or calixarenes.

There are also other organic phosphorus compounds derivatives being studied in different laboratories as extractants to recover uranium, including trioctylphosphine oxide (TOPO), dihexyl-N,N-diethylcarbamoyl-methylphosphonate (CMP), di-2ethylhexyl phosphoric acid (D2EHPA), monododecyl phosphoric acid (DDPA), glycerophosphate, and dibutyl butyl phosphonate (DBBP). Singh et al. (2016) elaborated the development of these organic phosphorus compounds for uranium extraction from phosphoric acid.

\subsection{Calixarene derivatives}

Calixarenes are composed by paraphenolic units attached through methylene bridges ortho to $\mathrm{OH}$ groups (Kiegiel et al. 2013). They are easily functionalized at phenol rings (upper) and phenolic $\mathrm{OH}$ groups (lower) rims to be more specific (Fig. 3a). With tunable cavities and versatile modifications, calixarenes and its derivatives are benign macrocyclic ligands of many metal ions, including U (Śliwa 2002; Shinkai et al. 1987; Kumar et al. 2016).

The coordinating ability and selectivity of calixarene derivatives for uranyl ions should be attributed to their structure arrangements and functionalization. Their sophisticated architectures with affinity ligand groups in benzene units exactly could provide the required pseudoplanar penta- and hexacoordinate structures for the coordination of uranyl ions (Kiegiel et al. 2013). To permit the penetration of linear $\mathrm{UO}_{2}{ }^{2+}$ into the calixarenes rings, exo-complex is firstly created, later changed into endo-complex after the high-energy conformation (Shinkai et al. 1987; Nagasaki et al. 1991), as shown in Fig. 3b. Advance characterization technologies (e.g. time-resolved laser fluorescence spectroscopy and extended X-ray absorption fine structure) provide powerful tools in the exploration of the coordination between calixarenes and uranyl ions. It is found that calixarene-based uranophiles usually form a 1:1 or 1:2 complex with 
Fig. 3 The structural illustration of calixarenes (a); the penetration of uranyl ions into calixarenes and the specific examples of endoand exocavity binding in calix[6] arene (b); some examples of reported calixarene derivatives 1-4 for uranium extraction (c) (Shinkai et al. 1987, 1989; Nagasaki and Shinkai 1991; Boulet et al. 2006)

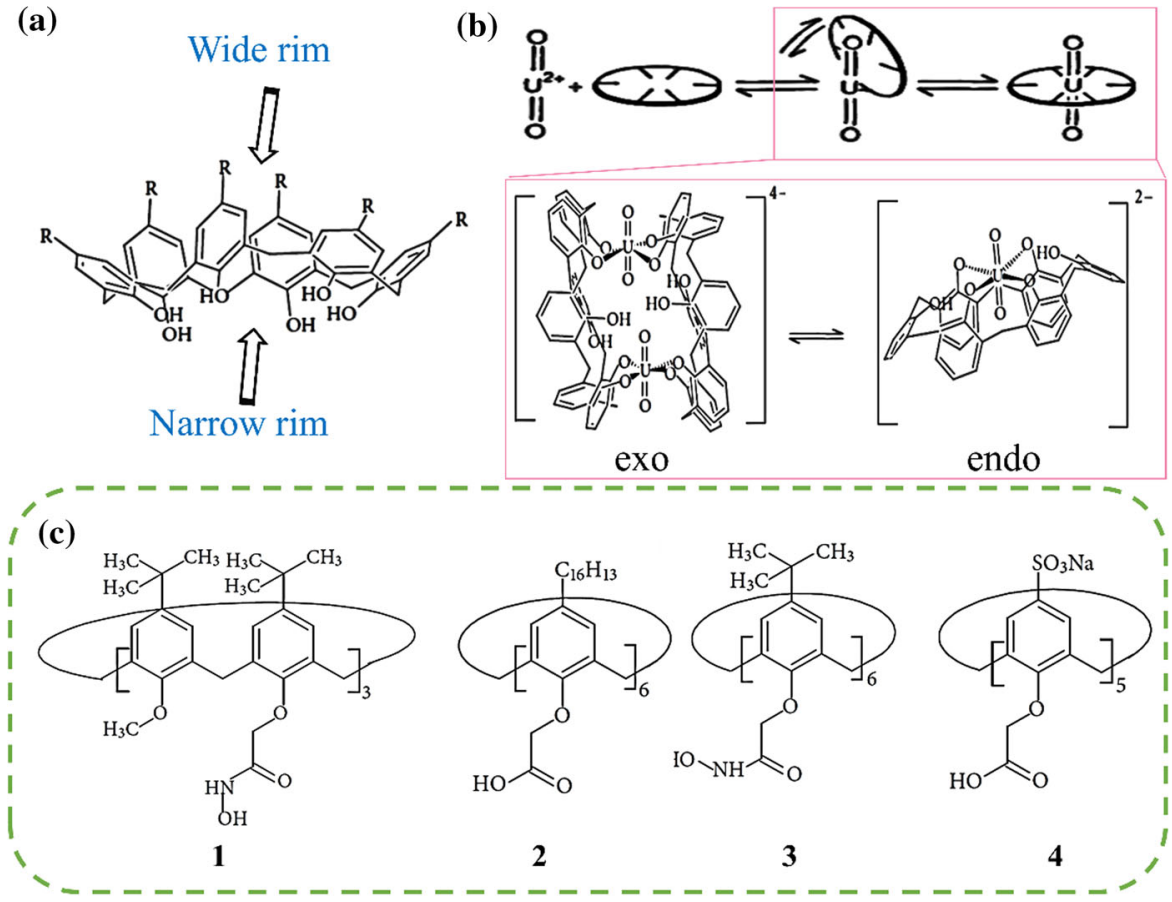

$\mathrm{UO}_{2}{ }^{2+}$ (Shinkai et al. 1987; Nagasaki et al. 1991). Furthermore, the presence of affinity ligands further contributes to their high efficiency. Calixarenes bearing ligands (e.g. $\mathrm{P}=\mathrm{O}$ groups) proved more efficient than classical extractants (e.g. TBP, TOPO, and CMPO) (Śliwa 2002). Compared to them, only $1 / 100$ to $1 / 10$ of ligand concentrations of such extracting agents could reach an assumed extraction yield.

Several types of calixarene derivatives have been studied as extractants for uranyl ions' separation at laboratories, but most are not yet in industrial application. Calix[4]arene derivatives containing hydroxamates, hydroxypyridinone (HOPO) (Leydier et al. 2008), acid-amide (Beer et al. 2002), sulfocatecholamide (CAMS) (Leydier et al. 2008) or CMPO, were expressively designed for the selective coordination of uranyl ions. HOPO and CAMS calixarenes are more efficient to coordinate with uranyl ions at acidic/neutral $\mathrm{pH}$ and basic $\mathrm{pH}$, respectively (Leydier et al. 2008). Additionally, the uranophile properties of calix[5]arene and calix[6]arene have aroused great interests (Shinkai et al. 1987). Kiegiel et al. (2013) elaborately summarized the finding of novel calixarene derivatives for uranyl extraction. More specific examples can be found in this review (Kiegiel et al.
2013). However, in most proposed process, the cost and toxic halogenated solvents is utilized, which is not acceptable in industrial utilization. Furthermore, calixarenes' behavior at irradiation is still under investigation despite good chemical stability (Shinkai et al. 1986).

\subsection{Amide type extractants}

Amides extracting agent composed of only $\mathrm{CHON}$ atoms is a type of green extractant because of its simplified synthetic routes and benign degradation products. With a strong polarity, the $-\mathrm{CO}-$ group in the structure exhibits a good coordination ability towards uranyl ions. This type of extractants is regarded as an attractive alternative to organophosphorus compounds.

Amide type extractants include monoamides, diamides, amide pod ethers, pyridine amides and others, whose general structures and specific examples are shown in Fig. 4. The nature of these extractants is related to their structures, which determines their extraction performance. For example, the longer the carbon chain of the substituent, the stronger the amide base. 
Fig. 4 The structure of general amides, diamides, single-pyridine amides and di-pyridine amides (a); and their specific examples (b)

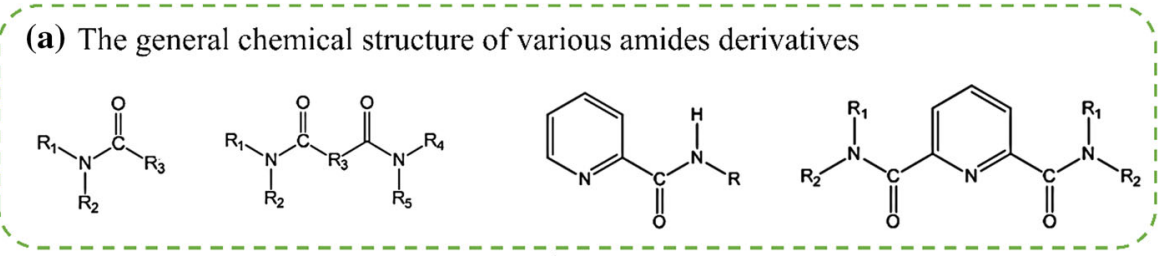

(b) Some examples of reported amides derivatives

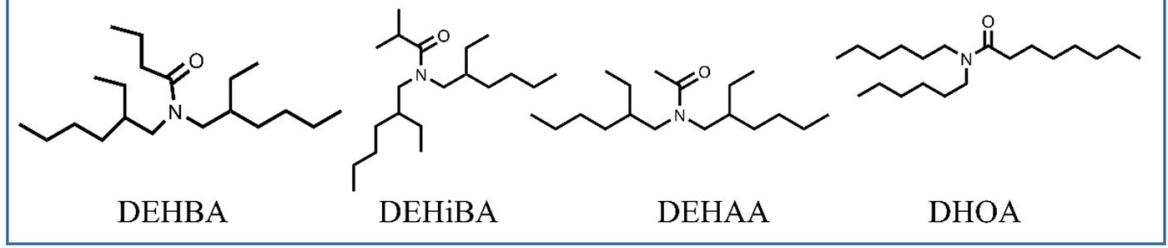

With only an amide group in its structure, the monoamide extracting agent could coordinate with metal ions with the help of its $\mathrm{N}$ or $\mathrm{O}$ atom separately or simultaneously. The alternation of alkyl groups on the monoamides could tune their extraction performance (Siddall 1960). For example, McCann et al. (2018) noticed that the straight chains of alkyl groups were more effective for hexavalent over tetravalent cations, whilst the performance of monoamides of branched chain of alkyl groups was the opposite. N,Ndihexyloctanamide (DHOA) is a typical monoamide compound (Drader et al. 2016). Compared to TBP, it exhibits more efficiency of U(VI) stripping using $0.01 \mathrm{M}$ nitric acid (Manchanda 2004) and lower partitioning towards contaminant elements. However, it is susceptible to radiolysis, too. Compared to monoamide extracting agent, diamide one presents the same merits but a higher extracting performance towards Am. There are also other $\mathrm{O}-\mathrm{N} \mathrm{N}$-donating ligands, such as Schiff base ligands, salon ligands, amides/diamides derivatives.

\section{Adsorption}

Adsorption is also a common technology for pollutants removal (Wang et al. 2018b; Wang and Zhuang 2019; Zhuang et al. 2019a, b), including uranyl ions. It is also regarded as the most promising method of uranium harvest from seawater (Abney et al. 2017). The removal of targeted pollutants into various adsorbents should be owing to various physicochemical interactions (Wang and Zhuang 2017). Among these forces, coordination is an important mechanism for the selective adsorption of various pollutants. The construction of adsorbents bearing affinity ligands is an efficient method for the efficiently adsorptive removal of targeted pollutants.

So far, various adsorbents bearing affinity organic ligands have been continuously reported for the selectively adsorptive removal of uranyl ions. The types of chelating ligands, supporting materials, and preparation methods have great effects on the adsorption performance towards uranyl ions.

Affinity ligands, including amidoxime, imidazole, and phosphoryl groups, together with the extractants developed in solvent extraction process, have been employed in adsorbents' construction. These organic ligands physically captured or chemically grafted into adsorbents greatly promote their adsorption selectivity and capacity towards uranyl ions. Among these coordinating agents, amidoxime group is the most popular one owing to its simple structure, good stability, and, most importantly, high coordinating selectivity towards uranyl ions. That makes amidoxime-based adsorbents the dominate materials for uranium harvest from seawater. There are also other types of O-/N-containing ligands for uranyl ions, but most of them also present adsorption towards other coexisting ions.

Besides these coordinating ligands, the solid carrier is also necessary component of adsorbents. Generally speaking, solid materials regardless of adsorption capacities can be applied as the carriers of the ligands as long as they are stable and modifiable. Carboni et al. (2013) deliberately chose mesoporous carbon with a negligible background sorption capacity of U(VI) as the supporting solids of the functionalized adsorbent 
for the head-to-head comparison of U(VI) binding capacity of nine different organic ligands. For the utilization in harsh conditions (e.g. extreme $\mathrm{pH}$ and radiation), they are also required of good chemical/ thermal and radiation stability. Various active groups (e.g. $-\mathrm{OH},-\mathrm{COOH}$, and $-\mathrm{NH}_{2}$ ) on their structures could be covalently connected with moieties of efficient ligands. Furthermore, structures of high porosity and surface area are favor for the impregnation of extractants, the exposure of grafting sites/moieties, or the diffusion of adsorbates.

As shown in Table 2, various organics, inorganics and magnetic composite have been utilized in the construction of adsorbents bearing specific organic ligands. Good stability, porous structure and cheap resources make silica (Vivero-Escoto et al. 2013; Zhao et al. 2014a), mesoporous carbon (Carboni et al. 2013), and carbon nanotubes (Sun et al. 2017; Wang et al. 2014; Wu et al. 2018; Tian et al. 2018, 2019) good inorganic carriers. Organic polymers with abundant functional groups, e.g., chitosan (Zhuang et al. 2018; Muzzarelli 2011), cellulose (Zhuang and Wang 2019) and polypropylene, could be chemically modified by various reactions to obtain desired coordinating structures. Additionally, the modification and application of commercial artificial polymers for versatile purposes is also widely studied. Notably, fibers (e.g. nylon textiles) have been employed as carriers of amidoxime groups in uranium harvest from seawater due to good mechanical strength, cheapness, and versatile utilization forms (Sugasaka et al. 1981; Ling et al. 2017; Tseng et al. 2009; Zhang et al. 2010). Additionally, the newly developed porous crystals, metal-organic frameworks (Li et al. 2018; Liu et al. 2017) and covalent organic frameworks (Sun et al. 2018), are also studied as porous decorating platforms for the grafting of amidoxime groups.

The adsorption process is affected by many factors, including the $\mathrm{pH}$ of the solutions, coexisting ions, concentration of metal ions, temperature, and others.
For example, higher remaining concentrations are observed at higher initial concentrations because of the limited adsorption sites, resulting in lower removal percentage of the U(VI). To date, adsorption has been regarded as the most promising technology for uranium recovery from seawater. The main difficulty of uranium adsorption lies in its low concentration relative to its coexisting ions. These coexisting ions may have competitive (e.g. V), coordinative (e.g. $\mathrm{CO}_{3}{ }^{2-}$ ), or ionic effect on uranium adsorption. Specially, due to the economical and ecologic reasons, the physicochemical characteristics of the seawater should not be adjusted by chemical additives or heating.

\subsection{Adsorbents bearing amidoxime ligands}

Amidoxime functional group has been widely recognized as the most promising ligand for uranium adsorption. In 1980s, Schenk et al. (1982) systematically screened more than 200 kinds of adsorbents with different functional groups for uranyl ion uptake. Among these adsorbents, crosslinked poly(acrylamidoximes) was highly appreciated owing to its stability in seawater and high adsorption selectivity and capacity of U(VI). This work is followed by substantial research focusing on amidoxime-based adsorbents (Zhuang et al. 2018; Wu et al. 2018; Zhao et al. 2014b; Yuan et al. 2016; Wang et al. 2018b; Cheng et al. 2019), and numerous reviews on amidoxime-based adsorbents for uranium harvest (Abney et al. 2017). So far, the countable marine experiments have all involved amidoxime-based polymer adsorbents (Gill et al. 2016; Ladshaw et al. 2017).

The outstanding affinity between the amidoxime groups and uranyl ions should be attributed to many aspects. According to the hard and soft acid and base theory, amidoxime group (the hard base functional groups) presents a strong chelating reaction for $U$ (the hard acid ions), leading to its effectively adsorptive

Table 2 The feature and types of carriers for the grafting or impregnation

\begin{tabular}{lll}
\hline Features & Categories & Details \\
\hline Porous & Organic types & Various resins, chitosan, cellulose, polypropylene, nylon textiles, covalent organic frameworks, etc. \\
Stable & Inorganic types & Silica, CNT, graphene (oxide) \\
modifiable & Hybrids & Magnetic-based composites, metal-organic frameworks, etc. \\
\hline
\end{tabular}


removal. Furthermore, the amidoxime group, $\mathrm{C}\left(\mathrm{NH}_{2}\right) \mathrm{NOH}$, is expected to coordinate with metal ions via its unpaired electrons of $\mathrm{N}$ or $\mathrm{O}$. So far, several binding motifs have been tentatively proposed as shown in Fig. 5a-d (Tian et al. 2012; Zhang et al. 2003; Katragadda et al. 1997; Choi and Nho 2000; Vukovic et al. 2012). Among these motifs, the theoretical results of the density functional theory indicated that $\eta^{2}$ binding motif (Fig. 5c) with the $\mathrm{N}-\mathrm{O}$ bond is the most stable form, and it was confirmed by the XRD results of uranyl ion complexes with benzamidoxime anions and acetamidoxime (Vukovic et al. 2012).

Figure 5e demonstrated the universal method of amidoxime grafting. Firstly, acrylonitrile and other co-monomers can be grafted into the various supports with the help of free radicals generated by physical or chemical methods (Zhuang et al. 2018). Then, cyano groups $(-\mathrm{CN})$ are converted into the desired amidoxime groups by the treatment of hydroxylamine and $\mathrm{KOH}$ conditioning. Compared with chemically initiated and thermally initiated polymerization, radiationinduced grafting polymerization (RIGP) exhibits good grafting ratio without additives. These advantages make RIGP widely adopted (Ladshaw et al. 2017).

Preparation conditions have a great influence on uranium adsorption capacity, including the radicals' generated methods, additives, monomers choosing, and the ratio of these monomers, as well as $\mathrm{KOH}$ conditioning concentration, duration, and temperature (Tian et al. 2013). The alkaline conditioning of the amidoxime-based adsorbents can significantly enhance its uranium adsorption capacities due to the following two reasons: (a) the alkaline treatment can convert amidoxime group into hydrophilic carboxylate groups, and (b) the open chain amidoxime groups can be changed into cyclic imidedioxime, which can compete with carbonate for uranyl ions at seawater $\mathrm{pH}$ effectively (Tian et al. 2013; Ivanov and Bryantsev 2016). Das et al. (2016) conducted a parametric study on the $\mathrm{KOH}$ concentration, conditioning time, and temperature in terms of uranium adsorption capacity. $\mathrm{Na}$ et al. (2012) explored the optimal conditions of photoirradiation-induced grafting of acrylonitrile onto polypropylene. In terms of uranium adsorption capacity, the optimal conditions proved to be: concentration

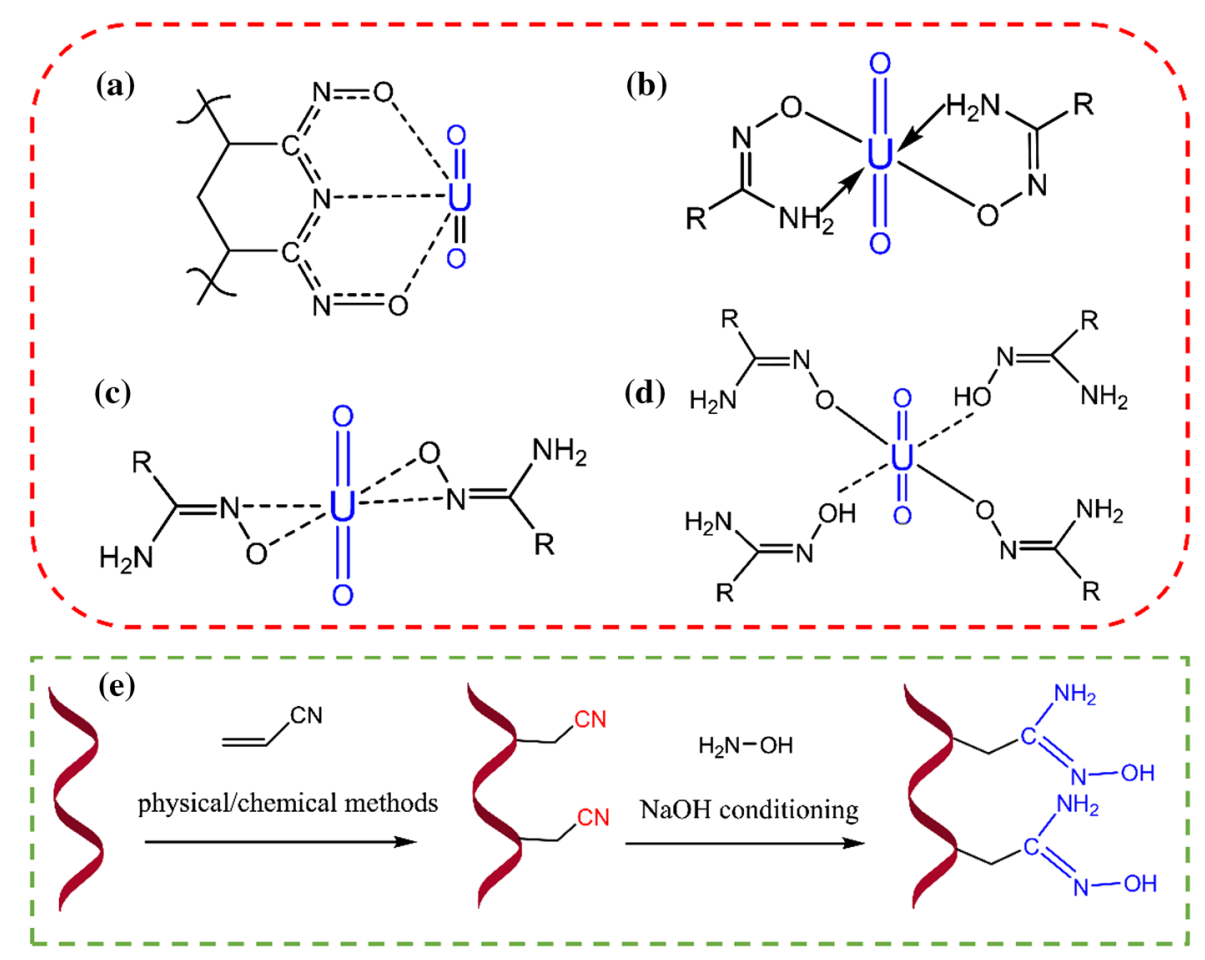

Fig. 5 The coordination motifs of amidoxime groups towards uranyl ions (a-d) (Tian et al. 2012; Zhang et al. 2003 ; Katragadda et al. 1997; Choi and Nho 2000; Vukovic et al. 2012); and the general method of amidoxime grafting (e) 
of acrylonitrile $\leq 1.0 \mathrm{M}$, a reaction time of $2 \mathrm{~h}$ and temperature of $60{ }^{\circ} \mathrm{C}$.

The structure of adsorbent also plays a vital role in its adsorption performance. Ordered porous structure presents superiority as a decorating platform, where high density and accessible functional groups could be grafted. In comparison with amorphous polymers with same chemical compositions, covalent organic frameworks bearing amidoxime groups presented a rapider adsorption equilibrium and a higher uptake of uranyl ions owing to its uniform pore structures (Sun et al. 2018). Additionally, nanostructure is found favor for adsorption. The blow spinning strategy was adopted to produce poly(imide dioxime) nanofiber, whose thickness can be controlled and its mechanical strength can be strengthened by weaving. The nanostructure fibers with abundant imide dioxime sites showed a recorded high adsorption capacity $(951 \mathrm{mg} / \mathrm{g})$ in uranium spiked seawater (8 ppm), as well as a high capacity $(8.7 \mathrm{mg} / \mathrm{g})$ in natural seawater after 56 days' exposure (Wang et al. 2018a).

Previously, our research group has grafted amidoxime groups into multiwalled carbon nanotubes (denoted as AO-MWCNTs) by RIGP method (Wu et al. 2018) and magnetic chitosan (denoted as MAOchitosan) by chemical method (Zhuang et al. 2018). The introduction of amidoxime groups greatly increased their adsorption capacities towards uranyl ions. Faster adsorption equilibrium was observed in the adsorption of uranyl ions by AO-MWCNTs owing to the porous structure of multiwalled carbon nanotubes; whilst MAO-chitosan presented a higher adsorption capacity and the advantages of magnetic separation owing to higher content of amidoxime groups and the presence of magnetic $\mathrm{Fe}_{3} \mathrm{O}_{4}$.

\subsection{Adsorbents bearing imidazole ligands}

Imidazole and its derivatives have also attracted much attention for uranium adsorption. Due to the structure similarity to amidoxime groups, the nitrogen atom of imidazole groups can also be the donor to uranyl ions (Schettini et al. 2012). Furthermore, compared to amidoxime, imidazole and its derivatives presents a lower toxicity.

So far, several kinds of its derivatives, such as vinylimidazole (Pekel and Güven 2003), benzimidazole (Kitagaki et al. 2016) and dihydroimidazole (DIM) (Yuan et al. 2012), have been grafted into
MOFs, $\mathrm{SiO}_{2}$, and other carriers, and they showed a good adsorption performance towards uranyl ions.

DIM was grafted into multiwalled nanotubes (MWCNTs) via silane coupling agent for the efficient uptake of uranyl ions, as shown in Fig. 6a (Tian et al. 2018). The pyridine-like nitrogen $(\mathrm{CH}=\mathrm{N}-\mathrm{CH})$ was found mainly responsible for the coordination of uranyl ions into adsorbent. Owing to the presence of DIM, a 3 times higher adsorption capacity towards uranyl ions than raw MWCNT was observed. Compared to AO-MWCNTs, it was less affected by vanadium, but more affected by carbonate.

The newly emerging 2D material, COFs, was also utilized as the decorating platform of benzimidazole by post modification (Fig. 6b) (Li et al. 2015). The asprepared adsorbent, denoted as COF-HBI, presented good a radiation resistance and thermostability, as well as fast adsorption equilibrium $(\sim 30 \mathrm{~min})$, high uptake capacity $(211 \mathrm{mg} / \mathrm{g})$, and $\mathrm{pH}$-dependent, endothermic and spontaneous adsorption process towards uranyl ions.
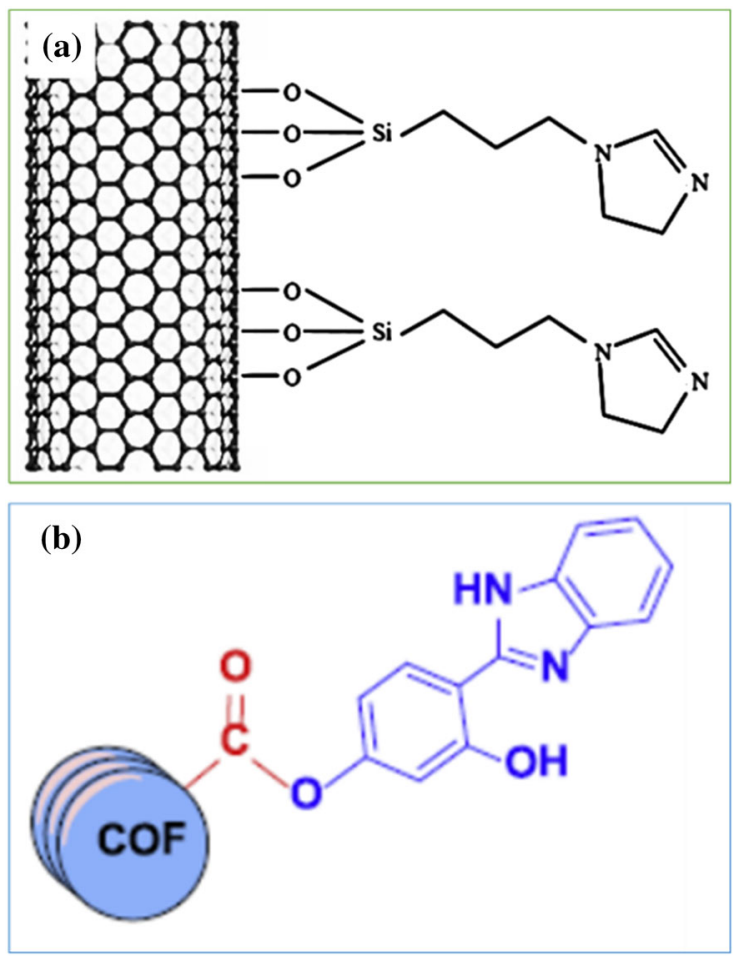

Fig. 6 The schematic diagrams of DIM-MWCNTs (a) and COF-HBI (b) 


\subsection{Adsorbents bearing phosphate ligands}

The immobilization of various phosphate ligands onto solids as adsorbents for uranium adsorption have been widely reported. The referred phosphate ligands here do not contain the organophosphorus compounds developed in solvent extraction (e.g. TBP). The O-donating phosphate ligands present a good coordinating ability in the adsorption of uranyl ions. In seawater, the rate-limiting step of uranyl ions' adsorption is the competition between ligands and carbonate. Compared to amidoxime groups, phosphate ligands can replace carbonate faster. However, besides uranyl ions, most phosphate derivative ligands also present good adsorption capacity towards other coexisting ions.

Phosphate-derivate immobilized on graphene oxides (GO) (Liu et al. 2015; Cai et al. 2017), chitosan, bacterial cellulose (Zhuang and Wang 2019), polyethylene (Shao et al. 2017), and silica (Lebed et al. 2011; Guo et al. 2017) have been reported, and they presented a good adsorption capacity for uranium, owing to the presence of phosphate-derivatives. Jayakumar et al. (2008) had a very short while useful review on the ten synthesis methods of phosphorylated chitin/chitosan, which could be used as a reference for the chemical modification of other adsorbents with phosphorylation. Specially, Shao et al. (2017) reported a uranium adsorption efficiency of $\sim 39 \%$ by $\mathrm{PO}_{4} / \mathrm{PE}$ mass on the condition of $25 \pm 1{ }^{\circ} \mathrm{C}, 24 \mathrm{~h}, 200 \mathrm{mg}$ adsorbents, and $100 \mathrm{~mL}$ seawater. This work indicates the great potential of phosphate-based adsorbents for uranium uptake.

Nine different organic ligands functionalized mesoporous silica have been synthesized and compared for uranium adsorptive removal (Vivero-Escoto et al. 2013). Among these adsorbents, phosphonate-functionalized one showed the highest adsorption capacity in the condition of water or artificial seawater. However, large amounts of nonspecific physic-sorption resulting from the surface hydroxyl of mesoporous silica made the rigorous interpretation difficult. To solve this problem, mesoporous carbon with a negligible background sorption capacity of U(VI) was chosen as the support of the functionalized adsorbent (Carboni et al. 2013). The head-to-head comparison of U(VI) binding capacity between various amidoxime, carboxyl and phosphoryl on innocent support was consistent with previous research, indicating that the phosphoric acid-functionalized adsorbents could be the promising alternative for uranium removal. Similar results are also observed in other research (Li et al. 2016). Additionally, the adsorption of uranyl ions onto $\mathrm{MC}-\mathrm{O}-\mathrm{PO}(\mathrm{OH})_{2}$ was greatly affected by the $\mathrm{pH}$ values, and the inflection point of $\mathrm{pH}$ was close to the $\mathrm{pKa}$ value of the sorbent group.

Phosphines with imidazol-2-yl moiety, which is the ligand of many transition metals, has been successfully immobilized onto adsorbents for uranium removal. The work has been reported by Budnyak et al. with a continuous process (Budnyak et al. 2016, 2018). Firstly, Benzoimidazol-2-yl-phenylphosphinic acid was immobilized on the silica as adsorbents for uranyl ions (Fig. 7a). Compared with other reported phosphonic acid derivatives, the as-prepared adsorbent showed a comparable adsorption capacity for U(VI) at neutral condition (Budnyak et al. 2016). Later, simpler derivatives, imidazol-2-yl-phosphonic acid, was immobilized on silica (Fig. 7b). The removal of benzene ring from the phosphines release the potential of phosphine coordinating with uranyl ions alone. This adsorbent was applied in acidic environment for uranium removal with a highest adsorption capacity exceeding $618 \mathrm{mg} \mathrm{g}^{-1}$ at $\mathrm{pH} 4$ (Budnyak et al. 2018).

\subsection{Adsorbents bearing extractants}

Compared with solvent extraction, solid adsorbents bearing organic compounds utilized in solvent extraction avoid organic solvents and the addition of other phase modifiers, as well as the associated problems (e.g. complicated operations, generation of thirdphase, and explosive hazards).

Extractants can be physically or covalently incorporated into supporting solids for the selective separation of uranyl ions. The physical impregnation of extractants into porous materials via intermolecular forces is simpler, but covalent attachment method minimizes the loss of extractants. Additionally, subtle changes in ligand sterics may lead to great change in its reactivity (Bart and Meyer 2008), especially taking into account the sophisticated extractants (e.g. calixarenes).

The porous structure and easy modification of silica lead to various types of silica-based adsorbents for the uranyl adsorption, including porous silica impregnated by polymers, functionalized by silanes, or 
Fig. 7 The schematic structures and uranium adsorption mechanism of silica with immobilized benzoimidazol-2-ylphenylphosphinic acid (Budnyak et al. 2016) (a) or imidazol-2yl-phosphonic acid (Budnyak et al. 2018)
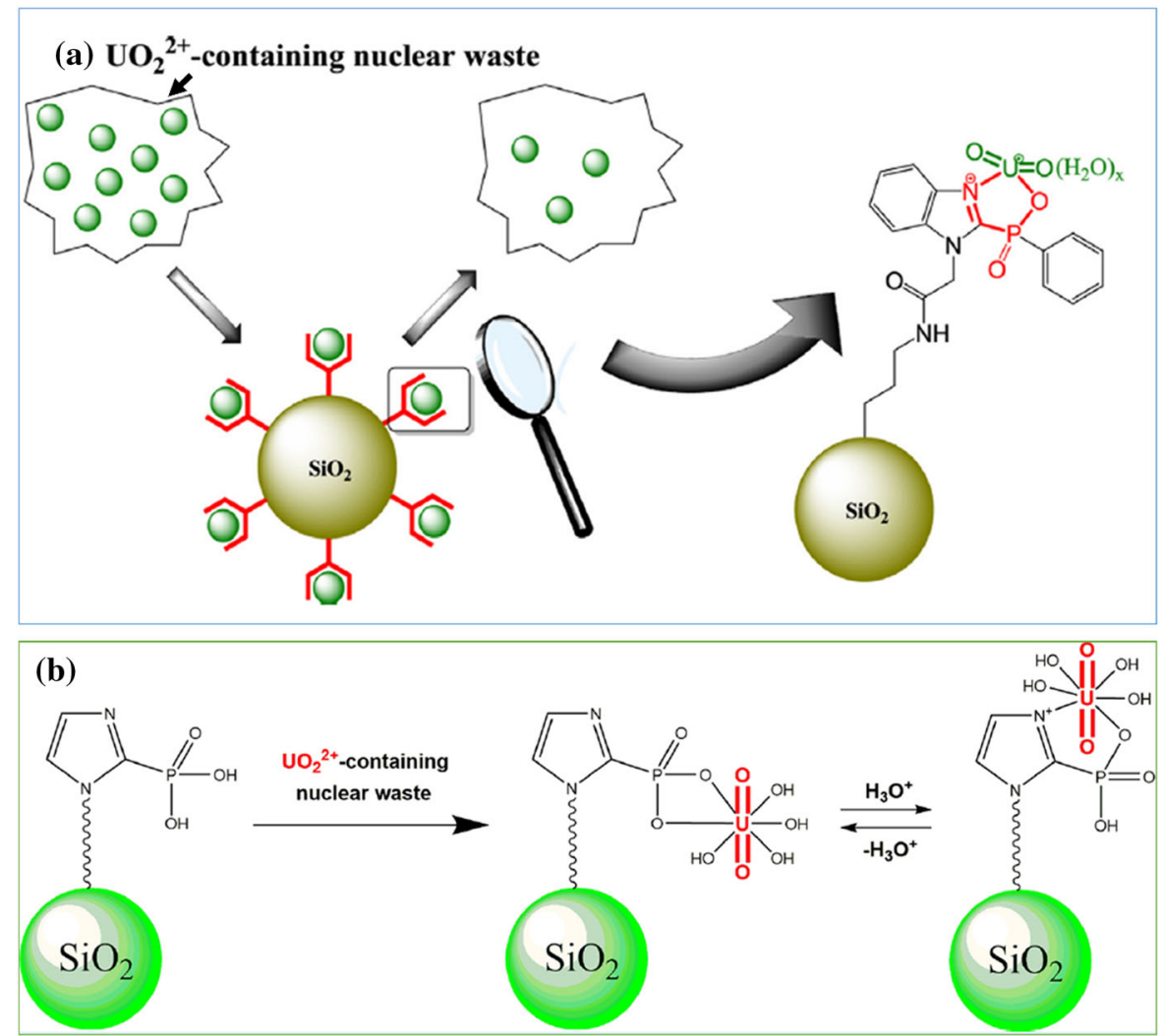

magnetized by incorporation of iron oxide (VeliscekCarolan 2016). Extractants are either impregnated into porous structure or appended into its frameworks by covalent silane anchor groups. In addition, carbon nanotubes and polyacrylonitrile were also impregnated by compounds developed in solvent extraction. The as-prepared adsorbents presented efficient recovery of uranyl ions from $\mathrm{HNO}_{3}$-leaching solution (Mokhodoeva et al. 2011).

Polymer resins composing of extractants immobilized in porous insoluble matrix have been utilized for separation at the back end of the nuclear fuel cycle. Natural polymer material (e.g. chitosan and alginate) and commercial Amberlite XAD 7 are widely utilized to synthesize resins (Aly and Hamza 2013). The choice of porous supporters has a significant effect on adsorption performance (Alexandratos 2009). Two type of commercial resins, Amberlite XAD 7 and $\mathrm{XAD} 4$, were compared as supporting materials for several types of monoamide compounds in terms of extraction performance towards uranyl ions. Results showed that acetyl amide extractants coated into XAD 7 was superior (Drader et al. 2016). Additionally, TBP immobilized in Amberlite XAD 7 and XAD 4, together with Levextrel OC 1023, are suggested for $\mathrm{U}$ and $\mathrm{Pu}$ separation from 3 to $5 \mathrm{M}$ nitric acids. The adsorption kinetics of CMPO impregnated into different types of polymer matrices are different from each other owing to the differences in functionality and porosity of their structures. Furthermore, these resins are required of good mechanical strength, chemical stability, and porosity, which can be tailored by the types/amounts of crosslinkers and comonomers (Alexandratos 2009).

Calix[4]arene derivative bearing benzhydrazide was covalently grafted into the silica-based magnetic nanoparticles for pollutants removal. In the proposed complexation motif, benzhydrazide on the upper rims was mainly responsible for uranyl ions' removal (Fig. 8). The magnetic core of as-prepared adsorbent made it easy in separation process (Sayin and Yilmaz 2011).

Nanofiber composed by polyacrylonitrile (PAN) and upper rim functionalized calix[4]arene bearing $\mathrm{N}$-methylglucamine (Calix-NMG) was obtained by electrospinning (Özcan et al. 2016). The presence of 
Fig. 8 The schematic diagram of adsorbent (BHCB-MN) and the suggested coordination mechanism towards uranyl ions

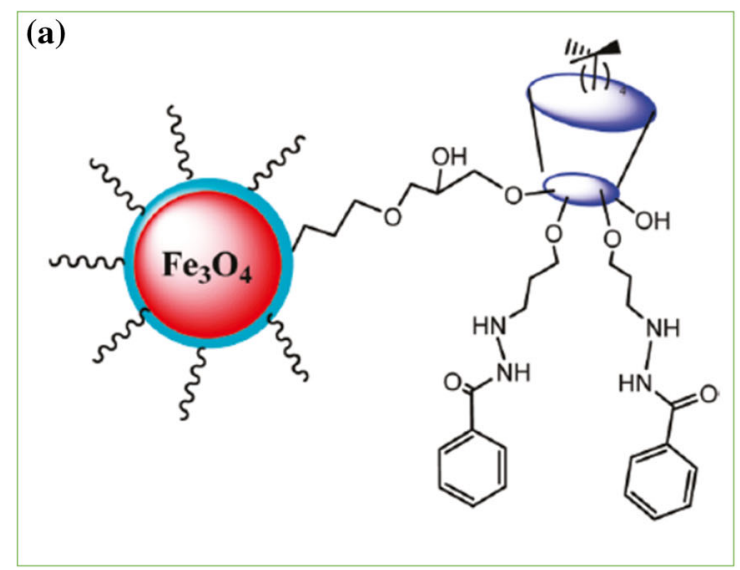

calix-NMG in the nanofibers converted the hydrophobic properties into hydrophilic, and increased its chelating ability of uranyl ions. Additionally, the durability advantages of this fiber made it feasible in separation.

\section{Concluding remarks and perspectives}

Radioactive uranium is not only a vital component of nuclear fuel, but also a chemically toxic and radioactive element. The recovery of uranium from aqueous solution have been extensively explored in order to recover the carbon-free resource or decrease its environmental risks from aqueous solutions.

Solvent extraction and adsorption are the most commonly used methods of uranium separation from aqueous solutions. The linear structure of uranyl ion and its feasibility in coordination with various ligands offer great opportunities for its adsorptive or extractive removal. For years, various kinds of affinity organic ligands of uranyl ions have been developed, including amidoxime, imidazole, amide, organophosphorus, and calixarene derivatives. The discovery of these affinity ligands and their utilization in both methods promote the development of the selective separation of uranyl ions. Searching for more efficient ligands of uranyl ions and exploring their feasibility in solvent extraction and adsorption are still the challenging work in future research.

Currently, tributyl phosphate and amidoxime group-based material has been regarded as the most promising extractant and adsorbent for the selective extraction and adsorption of uranyl ions, respectively.
TBP-based extraction processes for uranium separation from spent nuclear fuel have been put into industrial application with a commercial success; whilst amidoxime-based adsorbents make uranium recovery from seawater become a technologically viable alternative to terrestrial mining. Great efforts are being made to solve the defaults in both methods and searching for more efficient alternative materials or methods. Furthermore, there are other kinds of extractants (e.g. calixarene derivatives and amide types ligands) and adsorbents (imidazole-based, phosphate-based adsorbents) under development, yet most are in the initial stage far away from industrial application.

Affinity ligands-based technologies (e.g. adsorption and solvent extraction) are promising methods for the selectivity recovery of uranium despite of its low concentration in complicate aqueous environment. The progress of both technologies in the future research lies in the development of more effective ligands of higher affinity, stability, and compatibility in various systems. Furthermore, the exploration on their coordination chemistry towards uranyl ions and removal mechanisms by both methods would provide vital information for the development of new generation of ligands for uranyl ions.

Above all, the selective recovery of uranium from aqueous solutions is of great importance in terms of energy resource recovery and environmental protection. For the selective recovery of uranium, affinity ligands-based technologies (e.g. adsorption and solvent extraction) are developed and achieved great process, but are still facing many challenging. 
Acknowledgements The research was supported by the National Key Research and Development Program (2016YFC1402507), the National Natural Science Foundation of China (51578307) and the Program for Changjiang Scholars and Innovative Research Team in College (IRT-13026).

Open Access This article is distributed under the terms of the Creative Commons Attribution 4.0 International License (http:// creativecommons.org/licenses/by/4.0/), which permits unrestricted use, distribution, and reproduction in any medium, provided you give appropriate credit to the original author(s) and the source, provide a link to the Creative Commons license, and indicate if changes were made.

\section{References}

Abney CW, Mayes RT, Saito T, Dai S (2017) Materials for the recovery of uranium from seawater. Chem Rev 117:13935-14013

Alexandratos S (2009) Affinity of polymer-supported reagents for lanthanides as a function of donor atom polarizability. Ind Eng Chem Res 48:6173-6187

Aly MM, Hamza MF (2013) A review: studies on uranium removal using different techniques. Overview. J Dispers Sci Technol 34:182-213

Bart SC, Meyer K (2008) Highlights in uranium coordination chemistry. In: Albrecht-Schmitt TE (ed) Organometallic and coordination chemistry of the actinides. Springer, Berlin, pp 119-176

Beer PD, Brindley GD, Danny Fox O, Grieve A, Ogden MI, Szemes F, Drew MGB (2002) Acid-amide calixarene ligands for uranyl and lanthanide ions: synthesis, structure, coordination and extraction studies. $\mathrm{J}$ Chem Soc 16:3101-3111

Boulet B, Bouvier-Capely C, Cossonnet C, Cote G (2006) Solvent extraction of U(VI) by calix[6]arenes. Solvent Extr Ion Exch 24:319-330

Budnyak TM, Strizhak AV, Gladysz-Plaska A, Sternik D, Komarov IV, Kolodynska D, Majdan M, Tertykh VA (2016) Silica with immobilized phosphinic acid-derivative for uranium extraction. J Hazard Mater 314:326-340

Budnyak TM, Gladysz-Plaska A, Strizhak AV, Sternik D, Komarov IV, Majdan M, Tertykh VA (2018) Imidazole2yl-phosphonic acid derivative grafted onto mesoporous silica surface as a novel highly effective sorbent for uranium(VI) ion extraction. ACS Appl Mater Interfaces 10:6681-6693

Cai Y, Wu C, Liu Z, Zhang L, Chen L, Wang J, Wang X, Yang S, Wang S (2017) Fabrication of a phosphorylated graphene oxide-chitosan composite for highly effective and selective capture of U(VI). Environ Sci Nano 4:1876-1886

Carboni M, Abney CW, Taylor-Pashow KML, Vivero-Escoto JL, Lin W (2013) Uranium sorption with functionalized mesoporous carbon materials. Ind Eng Chem Res 52:15187-15197

Chareyron B, Živčič L, Tkalec T, Conde M (2014) Uranium mining. Unveiling the impacts of the nuclear industry. EJOLT report no. 15
Cheng Y, He P, Dong F, Nie X, Ding C, Wang S, Zhang Y, Liu $\mathrm{H}$, Zhou S (2019) Polyamine and amidoxime groups modified bifunctional polyacrylonitrile-based ion exchange fibers for highly efficient extraction of U(VI) from real uranium mine water. Chem Eng J 367:198-207

Choi SH, Nho YC (2000) Adsorption of $\mathrm{UO}_{2}{ }^{2+}$ by polyethylene adsorbents with amidoxime, carboxyl, and amidoxime/carboxyl group. Radiat Phys Chem 57:187-193

Cocalia VA, Jensen MP, Holbrey JD, Spear SK, Stepinski DC, Rogers RD (2005) Identical extraction behavior and coordination of trivalent or hexavalent f-element cations using ionic liquid and molecular solvents. Dalton Trans 11:1966-1971

Das S, Tsouris C, Zhang C, Kim J, Brown S, Oyola Y, Janke CJ, Mayes RT, Kuo LJ, Wood JR, Gill GA, Dai S (2016) Enhancing uranium uptake by amidoxime adsorbent in seawater: an investigation for optimum alkaline conditioning parameters. Ind Eng Chem Res 55:4294-4302

Denning RG (2007) Electronic structure and bonding in actinyl ions and their analogs. J Phys Chem A 111:4125-4143

Drader JA, Zhu L, Smith P, McCann K, Boyes S, Braley JC (2016) Assessment of monoamide extractants and solid supports as new extraction chromatographic materials. Sep Purif Technol 163:352-356

Gill GA, Kuo L-J, Strivens JE, Wood JR, Schlafer NJ, Janke CJ, Das S, Mayes R, Saito T, Brown SS, Tsouris C, Tsouris C, Wai CM, Pan H-B (2016) Summary of adsorption capacity and adsorption kinetics of uranium and other elements on amidoxime-based adsorbents from time series marine testing at the pacific northwest national laboratory. Report no. PNNL-25899. https://doi.org/10.2172/1330924

Guo X, Feng YR, Ma L, Gao DZ, Jing J, Yu JC, Sun HB, Gong HY, Zhang YJ (2017) Phosphoryl functionalized mesoporous silica for uranium adsorption. Appl Surf Sci 402:53-60

Husnain SM, Um W, Woojin L, Chang Y-S (2018) Magnetitebased adsorbents for sequestration of radionuclides: a review. RSC Adv 8:2521-2540

IAEA (1993) Uranium extraction technology. IAEA, Vienna. ISBN 92-0-103593-4

Ivanov AS, Bryantsev VS (2016) Assessing ligand selectivity for uranium over vanadium ions to aid in the discovery of superior adsorbents for extraction of $\mathrm{UO}_{2}{ }^{2+}$ from seawater. Dalton Trans 45:10744-10751

Jayakumar R, Selvamurugan N, Nair SV, Tokura S, Tamura H (2008) Preparative methods of phosphorylated chitin and chitosan-an overview. Int J Biol Macromol 43:221-225

Katragadda S, Gesser HD, Chow A (1997) The extraction of uranium by amidoximated orlon. Talanta 45:257-263

Katsoyiannis IA, Zouboulis AI (2013) Removal of uranium from contaminated drinking water: a mini review of available treatment methods. Desalin Water Treat 51:2915-2925

Kiegiel K, Steczek L, Zakrzewska-Trznadel G (2013) Application of calixarenes as macrocyclic ligands for uranium(VI): a review. J Chem 2013:1-16

Kim J, Tsouris C, Mayes RT, Oyola Y, Saito T, Janke CJ, Dai S, Schneider E, Sachde D (2013) Recovery of uranium from seawater: a review of current status and future research needs. Sep Sci Technol 48:367-387 
Kitagaki T, Kaneshiki T, Nomura M, Suzuki T (2016) Uranium separation from a simulant fuel debris solution using a benzimidazole-type anion exchange resin. J Nucl Sci Technol 53:1639-1646

Kolarik Z (2008) Complexation and separation of lanthanides(III) and actinides(III) by heterocyclic N-donors in solutions. Chem Rev 108:4208-4252

Kumar N, Leray I, Depauw A (2016) Chemically derived optical sensors for the detection of cesium ions. Coord Chem Rev 310:1-15

Ladshaw AP, Wiechert AI, Das S, Yiacoumi S, Tsouris C (2017) Amidoxime polymers for uranium adsorption: influence of comonomers and temperature. Materials 10:1268

Lanham WB, Runion TC (1949) Purex process for plutonium and uranium recovery. Report no. ORNL-479(Del.). O. R. N. Laboratory, Oak Ridge, TN

Lebed PJ, de Souza K, Bilodeau F, Lariviere D, Kleitz F (2011) Phosphonate-functionalized large pore 3-D cubic mesoporous (KIT-6) hybrid as highly efficient actinide extracting agent. Chem Commun 47:11525-11527

Leoncini A, Huskens J, Verboom W (2017) Ligands for f-element extraction used in the nuclear fuel cycle. Chem Soc Rev 46:7229-7273

Leydier A, Lecerclé D, Pellet-Rostaing S, Favre-Réguillon A, Taran F, Lemaire M (2008) Sequestering agents for uranyl chelation: new calixarene ligands. Tetrahedron 64:11319-11324

Li J, Yang XD, Bai CY, Tian Y, Li B, Zhang S, Yang XY, Ding SD, Xia CQ, Tan XY, Ma LJ, Li SJ (2015) A novel benzimidazole-functionalized 2-D COF material: synthesis and application as a selective solid-phase extractant for separation of uranium. J Colloid Interface Sci 437:211-218

Li D, Egodawatte S, Kaplan DI, Larsen SC, Serkiz SM, Seaman JC (2016) Functionalized magnetic mesoporous silica nanoparticles for $\mathrm{U}$ removal from low and high $\mathrm{pH}$ groundwater. J Hazard Mater 317:494-502

Li J, Wang X, Zhao G, Chen C, Chai Z, Alsaedi A, Hayat T, Wang X (2018) Metal-organic framework-based materials: superior adsorbents for the capture of toxic and radioactive metal ions. Chem Soc Rev 47:2322-2356

Lindner H, Schneider E (2015) Review of cost estimates for uranium recovery from seawater. Energy Econ 49:9-22

Ling CJ, Liu XY, Yang XJ, Hu JT, Li R, Pang LJ, Ma HJ, Li JY, Wu GZ, Lu SM, Wang DL (2017) Uranium adsorption tests of amidoxime-based ultrahigh molecular weight polyethylene fibers in simulated seawater and natural coastal marine seawater from different locations. Ind Eng Chem Res 56:1103-1111

Liu X, Li JX, Wang XX, Chen CL, Wang XK (2015) High performance of phosphate-functionalized graphene oxide for the selective adsorption of U(VI) from acidic solution. J Nucl Mater 466:56-64

Liu JM, Liu T, Wang CC, Yin XH, Xiong ZH (2017) Introduction of amidoxime groups into metal-organic frameworks to synthesize MIL-53(Al)-AO for enhanced U(VI) sorption. J Mol Liq 242:531-536

Madic C, Boullis B, Baron P, Testard F, Hudson MJ, Liljenzin JO, Christiansen B, Ferrando M, Facchini A, Geist A, Modolo G, Espartero AG, De Mendoza J (2007) Futuristic back-end of the nuclear fuel cycle with the partitioning of minor actinides. J Alloys Compd 444:23-27
Manchanda V (2004) Amides and diamides as promising extractants in the back end of the nuclear fuel cycle: an overview. Sep Purif Technol 35:85-103

McCann K, Sinkov SI, Lumetta GJ, Shafer JC (2018) Inner versus outer sphere metal-monoamide complexation: ramifications for tetravalent \& hexavalent actinide selectivity. New J Chem 42:5415-5424

Mincher BJ, Modolo G, Mezyk SP (2009) The effects of radiation chemistry on solvent extraction: 1. Conditions in acidic solution and a review of TBP radiolysis. Solvent Extr Ion Exch 27:1-25

Mokhodoeva OB, Myasoedova GV, Zakharchenko EA (2011) Solid-phase extractants for radionuclide preconcentration and separation. New Possibilities. Radiochemistry 53:35-43

Muzzarelli RAA (2011) Potential of chitin/chitosan-bearing materials for uranium recovery: an interdisciplinary review. Carbohydr Polym 84:54-63

Na CK, Park HJ, Kim BG (2012) Optimal amidoximation conditions of acrylonitrile grafted onto polypropylene by photoirradiation-induced graft polymerization. J Appl Polym Sci 125:776-785

Nagasaki T, Shinkai S (1991) Synthesis and solvent-extraction studies of novel calixarene-based uranophiles bearing hydroxamic groups. J Chem Soc 7:1063-1066

Nagasaki T, Kawano K, Araki K, Shinkai S (1991) Kinetic studies of calixarene-based cyclic and non-cyclic 'superuranophiles'. J Chem Soc 9:1325-1327

Özcan F, Bayrakc1 M, Ertul Ş (2016) Synthesis and characterization of novel nanofiber based calixarene and its binding efficiency towards chromium and uranium ions. J Incl Phenom Macrocycl Chem 85:49-58

Paiva AP, Malik P (2004) Recent advances on the chemistry of solvent extraction applied to the reprocessing of spent nuclear fuels and radioactive wastes. J Radioanal Nucl Chem 261:485-496

Pekel N, Güven O (2003) Separation of uranyl ions with amidoximated poly(acrylonitrile/N-vinylimidazole) complexing sorbents. Colloids Surf A 212:155-161

Sartain HT, McGraw SN, Lawrence CL, Werner EJ, Biros SM (2015) A novel tripodal CMPO ligand: affinity for f-elements, computational investigations and luminescence properties. Inorg Chim Acta 426:126-135

Sayin S, Yilmaz M (2011) Synthesis of a new calixarene derivative and its immobilization onto magnetic nanoparticle surfaces for excellent extractants toward $\mathrm{Cr}(\mathrm{VI})$, As(V), and U(VI). J Chem Eng Data 56:2020-2029

Schenk HJ, Astheimer L, Witte EG, Schwochau K (1982) Development of sorbers for the recovery of uranium from seawater. 1. Assessment of key parameters and screening studies of sorber materials. Sep Sci Technol 17:1293-1308

Schettini MF, Wu G, Hayton TW (2012) Synthesis and reactivity of a uranyl-imidazolyl complex. Chem Commun 48:1484-1486

Shao DD, Li YY, Wang XL, Hu S, Wen J, Xiong J, Asiri AM, Marwani HM (2017) Phosphate-functionalized polyethylene with high adsorption of uranium(VI). ACS Omega 2:3267-3275

Shinkai S, Koreishi H, Ueda K, Manabe O (1986) A new hexacarboxylate uranophile derived from calix[G]arene. J Chem Soc Chem Commun 3:233-234 
Shinkai S, Koreishi H, Ueda K, Arimura T, Manabe O (1987) Molecular design of calixarene-based uranophiles which exhibit remarkably high stability and selectivity. J Am Chem Soc 109:6371-6376

Shinkai S, Shiramama Y, Satoh H, Manabe O, Arimura T, Fujimoto K, Matsuda T (1989) Selective extraction and transport of $\mathrm{UO}_{2}{ }^{2+}$ with calixarene-based uranophiles. J Chem Soc 8:1167-1171

Siddall TH (1960) Effects of structure of n, n-disubstituted amides on their extraction of actinide and zirconium nitrates and of nitric acid. J Phys Chem 64:1863-1866

Singh DK, Mondal S, Chakravartty JK (2016) Recovery of uranium from phosphoric acid: a review. Solvent Extr Ion Exch 34:201-225

Śliwa W (2002) Calixarene complexes with transition metal, lanthanide and actinide ions. Croat Chem Acta 75:131-153

Sood DD, Patil SK (1996) Chemistry of nuclear fuel reprocessing: current status. J Radioanal Nucl Chem 203:547-573

Stockmann TJ, Ding Z (2011) Uranyl ion extraction with conventional PUREX/TRUEX ligands assessed by electroanalytical chemistry at micro liquid/liquid interfaces. Anal Chem 83:7542-7549

Sugasaka K, Katoh S, Takai N, Takahashi H, Umezawa Y (1981) Recovery of uranium from seawater. Sep Sci Technol 16:971-985

Sun YB, Lu SH, Wang XX, Xu C, Li JX, Chen CL, Chen J, Hayat T, Alsaedi A, Alharbi NS, Wang X (2017) Plasmafacilitated synthesis of amidoxime/carbon nanofiber hybrids for effective enrichment of U-238(VI) and Am241(III). Environ Sci Technol 51:12274-12282

Sun Q, Aguila B, Earl LD, Abney CW, Wojtas L, Thallapally PK, Ma SQ (2018) Covalent organic frameworks as a decorating platform for utilization and affinity enhancement of chelating sites for radionuclide sequestration. Adv Mater 30:1705479

Tian G, Teat SJ, Zhang Z, Rao L (2012) Sequestering uranium from seawater: binding strength and modes of uranyl complexes with glutarimidedioxime. Dalton Trans 41:11579-11586

Tian G, Teat SJ, Rao L (2013) Thermodynamic studies of U(VI) complexation with glutardiamidoxime for sequestration of uranium from seawater. Dalton Trans 42:5690-5696

Tian K, Wu JL, Wang JL (2018) Adsorptive extraction of uranium (VI) from seawater using dihydroimidazole functionalized multiwalled carbon nanotubes. Radiochim Acta 106:719-731

Tian K, Zhuang ST, Wu JL, Wang JL (2019) Metal organic framework (La-PDA) as an effective adsorbent for the removal of uranium(VI) from aqueous solution. Radiochim Acta. https://doi.org/10.1515/ract-2019-3145

Tseng H-J, Hsu S-H, Wu M-W, Hsueh T-H, Tu P-C (2009) Nylon textiles grafted with chitosan by open air plasma and their antimicrobial effect. Fibers Polym 10:53-59

Veliscek-Carolan J (2016) Separation of actinides from spent nuclear fuel: a review. J Hazard Mater 318:266-281

Vivero-Escoto JL, Carboni M, Abney CW, deKrafft KE, Lin W (2013) Organo-functionalized mesoporous silicas for efficient uranium extraction. Microporous Mesoporous Mater $180: 22-31$
Vukovic S, Watson LA, Kang SO, Custelcean R, Hay BP (2012) How amidoximate binds the uranyl cation. Inorg Chem 51:3855-3859

Wang JL, Zhuang ST (2017) Removal of various pollutants from water and wastewater by modified chitosan adsorbents. Crit Rev Environ Sci Technol 47:2331-2386

Wang JL, Zhuang ST (2019) Removal of cesium ions from aqueous solutions using various separation technologies. Rev Environ Sci Bio/Technol 18:231-269

Wang Y, Gu ZX, Yang JJ, Liao JL, Yang YY, Liu N, Tang J (2014) Amidoxime-grafted multiwalled carbon nanotubes by plasma techniques for efficient removal of uranium (VI). Appl Surf Sci 320:10-20

Wang D, Song JA, Wen J, Yuan YH, Liu ZL, Lin S, Wang HY, Wang HL, Zhao SL, Zhao XM, Fang MH, Lei M, Li B, Wang N, Wang XL, Wu H (2018a) Significantly enhanced uranium extraction from seawater with mass produced fully amidoximated nanofiber adsorbent. Adv Energy Mater 8:1802607

Wang JL, Zhuang ST, Liu Y (2018b) Metal hexacyanoferratesbased adsorbents for cesium removal. Coord Chem Rev 374:430-438

Wu JL, Tian K, Wang JL (2018) Adsorption of uranium (VI) by amidoxime modified multiwalled carbon nanotubes. Prog Nucl Energy 106:79-86

Yuan LY, Liu YL, Shi WQ, Li Z, Lan JH, Feng YX, Zhao YL, Yuan YL, Chai ZF (2012) A novel mesoporous material for uranium extraction, dihydroimidazole functionalized SBA-15. J Mater Chem 22:17019

Yuan D, Chen L, Xiong X, Yuan L, Liao S, Wang Y (2016) Removal of uranium (VI) from aqueous solution by amidoxime functionalized superparamagnetic polymer microspheres prepared by a controlled radical polymerization in the presence of DPE. Chem Eng J 285:358-367

Zhang A, Asakura T, Uchiyama G (2003) The adsorption mechanism of uranium(VI) from seawater on a macroporous fibrous polymeric adsorbent containing amidoxime chelating functional group. React Funct Polym 57:67-76

Zhang H, Wu C, Zhang Y, White CJB, Xue Y, Nie H, Zhu L (2010) Elaboration, characterization and study of a novel affinity membrane made from electrospun hybrid chitosan/ nylon-6 nanofibers for papain purification. J Mater Sci 45:2296-2304

Zhao Y, Li J, Zhao L, Zhang S, Huang Y, Wu X, Wang X (2014a) Synthesis of amidoxime-functionalized $\mathrm{Fe}_{3} \mathrm{O}_{4} @$ $\mathrm{SiO}_{2}$ core-shell magnetic microspheres for highly efficient sorption of U(VI). Chem Eng J 235:275-283

Zhao YG, Li JX, Zhang SW, Wang XK (2014b) Amidoximefunctionalized magnetic mesoporous silica for selective sorption of U(VI). RSC Adv 4:32710-32717

Zhuang ST, Wang JL (2019) Removal of U(VI) from aqueous solution using phosphate functionalized bacterial cellulose as efficient adsorbent. Radiochim Acta 107:459-467

Zhuang ST, Cheng R, Kang M, Wang JL (2018) Kinetic and equilibrium of $\mathrm{U}(\mathrm{VI})$ adsorption onto magnetic amidoximefunctionalized chitosan beads. J Clean Prod 188:655-661

Zhuang ST, Liu Y, Wang JL (2019a) Mechanistic insight into the adsorption of diclofenac by MIL-100: experiments and theoretical calculations. Environ Pollut 253:616-624 
Zhuang ST, Cheng R, Wang JL (2019b) Adsorption of diclofenac from aqueous solution using UiO-66-type metal-organic frameworks. Chem Eng J 359:354-362
Publisher's Note Springer Nature remains neutral with regard to jurisdictional claims in published maps and institutional affiliations. 